\title{
ZSTK474, a PI3K inhibitor, suppresses proliferation and sensitizes human pancreatic adenocarcinoma cells to gemcitabine
}

\author{
HONG-QUAN DUONG ${ }^{1}$, HEE JEONG KIM ${ }^{1}$, HYO JIN KANG ${ }^{1}$, YEON-SUN SEONG ${ }^{3}$ and INSOO BAE ${ }^{1-3}$ \\ Departments of ${ }^{1}$ Oncology and ${ }^{2}$ Radiation Medicine, Lombardi Comprehensive Cancer Center, \\ Georgetown University, Washington DC 20057, USA; ${ }^{3}$ WCU (World Class University) Research \\ Center of Nanobiomedical Science, Dankook University, Cheonan, Republic of Korea
}

Received July 26, 2011; Accepted September 12, 2011

DOI: $10.3892 /$ or.2011.1503

\begin{abstract}
The phosphatidylinositol 3-kinase (PI3K)/Akt signaling pathway is important in cell proliferation and survival, and it is frequently and aberrantly activated in pancreatic adenocarcinoma. Potential anti-tumor effect(s) of ZSTK474, a PI3K/Akt inhibitor, together with a key clinically relevant antitumor agent, gemcitabine (GEM), have been reported in a human pancreatic cancer xenograft mouse model. However, the precise molecular mechanism of these anti-tumor effects has not been well elucidated. In this study, we investigated the molecular mechanism of GEM plus ZSTK474 in reducing tumor cell survival in human pancreatic cancer cell lines. Our study showed that ZSTK474 inhibited cell growth by arresting cells at the $\mathrm{G}_{1}$ phase and by inducing apoptosis. ZSTK474 also inhibited the phosphorylation of Akt, GSK3 $\beta$ and BAD. The combination of GEM and ZSTK474 demonstrated synergistic anti-tumor effects on pancreatic cancer cells in both transient (3 days) and long-term (14 days) clonogenic assays. Thus, we elucidated the potential molecular mechanism leading to the enhanced anti-tumor effect when GEM and ZSTK474 are combined in treatment.
\end{abstract}

\section{Introduction}

Pancreatic adenocarcinoma is one of the most common causes of cancer-related deaths in developed countries $(1,2)$. It is one of the most aggressive human solid tumors with an extremely poor prognosis because of its aggressive invasion, early metastasis and resistance to existing chemotherapy and radiotherapy (3-5). Since gemcitabine (GEM) was introduced as an anti-tumor agent in 1996, it has been used as the standard first-line chemotherapeutic agent for the treatment of advanced and metastatic pancreatic cancer (6). However, its therapeutic efficacy seems

Correspondence to: Dr Insoo Bae, Department of Oncology, Lombardi Comprehensive Cancer Center, Georgetown University, Washington DC 20057, USA

E-mail: ib42@georgetown.edu

Key words: phosphatidylinositol 3-kinase/Akt pathway, ZSTK474, gemcitabine, apoptosis, human pancreatic adenocarcinoma marginal and pancreatic cancer easily acquires resistance to GEM after a few cycles of administration (7).

There are multiple signaling pathways that could potentially enhance the growth and proliferation of pancreatic cancer, including nuclear factor $\kappa \mathrm{B}(\mathrm{NF}-\kappa \mathrm{B})$, phosphatidylinositol3-kinase (PI3K)/Akt, and mitogen-activated protein kinase (MAPK). Moreover, the PI3K/Akt pathway has been reported as an important factor in conferring chemoresistance to GEM in pancreatic cancer $(8,9)$. The pathway for PI3K is activated by various extracellular signals and leads to the phosphorylation of Akt and its downstream effectors (10). When Akt is phosphorylated, it, in turn, phosphorylates a variety of proteins leading to cell survival and proliferation (10). In addition, Akt is reported to be constitutively overexpressed in various pancreatic cancer cell lines (11).

Several previous studies have indicated that LY294002 and Wortmannin, classical inhibitors of the PI3K/Akt pathway, can increase drug sensitivity in pancreatic adenocarcinoma cells in vitro and in vivo (12). Inhibition of the PI3K/Akt pathway by LY294002 or Wortmannin enhances GEM-induced apoptosis in human pancreatic cancer cells (8). Therefore, the PI3K/ Akt pathway may play a significant role in mediating drug resistance and is a promising target for therapeutic intervention in human pancreatic cancer $(8,12)$. Although these classic PI3K/Akt inhibitors have therapeutic potential when used either by themselves or in combination with GEM in the treatment of pancreatic cancer, the severe cytotoxicity observed in preclinical animal studies limit their use for clinical trials (13). Accordingly, screening and identification of significantly effective novel PI3K/Akt inhibitor(s) to enhance clinical efficacy are important.

ZSTK474 is a pan-PI3K inhibitor, synthesized by Zenyaku Kogyo Co., Ltd. (Tokyo, Japan) and can be given orally (14). It has shown potent anti-tumor activity against human cancer xenografts without toxic effects in critical organs (15). ZSTK474 has been reported to inhibit 39 human cancer cell lines including lung, stomach, ovarian, renal, colon, breast, brain, prostate cancer and melanoma in vitro $(16,17)$. Most notably, ZSTK474 competed with ATP to inhibit all four p110 isoforms of PI3K subunits with $\mathrm{IC}_{50}$ values of $16,44,5$ and $49 \mathrm{nmol}$ for $\mathrm{p} 110 \alpha,-\beta,-\delta$ and $-\gamma$, respectively (18). Inhibition of PI3K by ZSTK474 suppressed tumor growth not via apoptosis, but by $G_{0} / G_{1}$ arrest in prostate, lung, glioblastoma and colorectal 
cancer lines (19). In addition, ZSTK474 specifically inhibits PI3K without targeting other types of protein kinases such as the PI3K-related kinases mammalian target of rapamycin (mTOR) and DNA-activated protein kinase (DNA-PK) $(15,18)$.

In this study, we examined the anti-tumor efficacy of ZSTK474 in several human pancreatic cancer cell lines and also investigated the combination effects of ZSTK474 with various chemotherapeutic agents such as GEM and 5-FU. The aim of our study was to investigate the molecular mechanism of ZSTK474 alone or with GEM in suppressing growth.

\section{Materials and methods}

Cell culture and reagents. MIA $\mathrm{PaCa}-2$ and $\mathrm{BxPC}-3$ cells were purchased from American Type Culture Collection (ATCC, Manassas, VA), and AsPC-1 and Colo-357 cells were obtained from the Tissue Culture Shared Resource of Georgetown University Medical School (GUMC; Washington, DC). AsPC-1, BxPC-3 and Colo-357 cells were cultured in RPMI-1640 media supplemented with fetal bovine serum (FBS; $20 \%$ for AsPC-1 and 10\% for Colo-357 and BxPC-3 cells), $100 \mathrm{U} / \mathrm{ml}$ penicillin, $100 \mu \mathrm{g} / \mathrm{ml}$ streptomycin and $1 \%$ sodium pyruvate. MIA PaCa-2 cells were cultured in Dulbecco's modified Eagle's medium (DMEM) containing 10\% FBS, 2.5\% horse serum (HS), $100 \mathrm{U} / \mathrm{ml}$ penicillin, and $100 \mu \mathrm{g} / \mathrm{ml}$ streptomycin. All cell culture reagents were purchased from BioWhittaker (Walkersville, MD). ZSTK474 was purchased from LC Laboratories (Woburn, MA), and GEM was obtained from Sigma (St. Louis, MO).

3-(4,5-Dimethylthiazol-2-yl)-2,5-diphenyltetrazolium bromide (MTT) assay and determination of the combination index (CI). A total of 2,500 human pancreatic cancer cells were plated in 96-well flat bottom plates and then exposed to test agents in various concentrations. At the indicated times, $10 \mu \mathrm{l}$ of $1 \mathrm{mg} / \mathrm{ml}$ MTT (Sigma) in PBS was added to each well for $4 \mathrm{~h}$. After centrifugation and removal of the medium, $150 \mu \mathrm{l}$ of DMSO (Sigma) was added to each well to dissolve the formazan crystals. The absorbance was measured at $540 \mathrm{~nm}$ using an ELx808 absorbance microplate reader (BioTek Instruments, Inc., Winooski, VT). Absorbance of untreated cells was designated as $100 \%$ and cell survival was expressed as a percentage of this value. Triplicate wells were assayed for each condition and the standard deviation (SD) was determined. The drug interaction was evaluated by using the combination index (CI) according to the method of Chou and Talalay (20). For each combination experiment, the CI number was calculated by using the CompuSyn software (ComboSyn, Inc., Paramus, $\mathrm{NJ}$ ) and values of $\mathrm{CI}<1, \mathrm{CI}=1, \mathrm{CI}>1$ indicated synergism, additive effect, and antagonism, respectively.

Western blot (WB) analysis. Cells were grown to $\sim 70 \%$ confluence and reagents were added at the indicated concentrations. After exposure to ZSTK474 alone or in combination with GEM, cells were lysed in cell lysis buffer containing $20 \mathrm{mM}$ Tris- $\mathrm{HCl}, 0.5 \mathrm{M} \mathrm{NaCl}, 0.25 \%$ Triton $\mathrm{X}-100,1 \mathrm{mM}$ EDTA, $1 \mathrm{mM}$ EGTA, $10 \mathrm{mM} \beta$-glycophosphate, $10 \mathrm{mM} \mathrm{NaF}, 300 \mu \mathrm{M}$ $\mathrm{Na}_{3} \mathrm{VO}_{4}, 1 \mathrm{mM}$ benzamidine, $2 \mu \mathrm{M}$ PMSF, and $1 \mathrm{mM}$ DTT. Protein concentrations were determined by a BCA protein assay kit (Thermo Scientific, Rockford, IL). Proteins were separated by SDS-PAGE, transferred on to PVDF membranes, blocked in $1 \mathrm{X}$ blocking buffer (Sigma) and probed with the following primary antibodies: phospho-GSK3 $\beta$ (S9), GSK3 $\beta$, phospho-Akt (S473), Akt, phospho-BAD (S112), BAD (Cell Signaling Technology, Inc., Boston, MA), PARP (BD Biosciences, Franklin Lakes, NJ), and $\alpha$-tubulin (Sigma). Then, the membranes were incubated with horseradish peroxidase (HRP)-conjugated secondary antibodies (Sigma) and visualized with a chemiluminescence kit (Santa Cruz Biotechnology, Santa Cruz, CA) according to the manufacturer's instructions and exposed to X-ray film (American X-ray Corp., Louisville, $\mathrm{TN})$.

Clonogenic assay. Human pancreatic cancer cells (4x10 5 cells) were seeded in $60-\mathrm{cm}$ dishes. Twenty-four hours after plating, varying concentrations of the drugs, either as a single agent or in combination, were added to the dishes. After treatment, cells (2,000 cells) were re-seeded in 60-cm dishes (triplicate). Each culture dish was incubated for 14 days and photographed after staining with $0.5 \%$ crystal violet in PBS including $25 \%$ methanol. Colonies were examined under a light microscope and counted after capturing images by scanner. Colony numbers were calculated according to the percentage of the untreated cells.

Flow cytometry. Human pancreatic cancer cell lines were collected after treatment of ZSTK474 with or without GEM by trypsinization, washed with PBS and fixed overnight in $70 \%$ ethanol at $-20^{\circ} \mathrm{C}$. Cells were then incubated with $20 \mu \mathrm{g} / \mathrm{ml}$ propidium iodide and $40 \mu \mathrm{g} / \mathrm{ml}$ RNase A in 1X PBS. Cells were analyzed on a FACSCalibur flow cytometer (BectonDickinson, CA). The acquired data were analyzed by Cell Quest Pro Analysis software (Becton-Dickinson).

Caspase-3 activity assay. The caspase-3 activity assay was carried out by using a caspase-3/CPP32 colorimetric assay kit (BioVision, Mountain View, CA) according to the manufacturer's instructions. Cells were treated with ZSTK474 or in combination with GEM with indicated concentrations for $48 \mathrm{~h}$. Approximately $100 \mu \mathrm{g}$ of protein was incubated with $200 \mu \mathrm{M}$ Asp-Glu-Val-Asp-p-nitroanilide (DEVD-pNA) and $10 \mathrm{mM}$ DTT at $37^{\circ} \mathrm{C}$ for $2 \mathrm{~h}$. Absorbance was measured at $405 \mathrm{~nm}$ using an ELx808 absorbance microplate reader. Increasing percentage in CPP32 activity was determined by calculating these results in comparison with the percentage of uninduced control samples.

Statistical analysis. Statistical comparisons were made using the two-tailed Student's t-test where appropriate. Results were considered significant in all experiments at ${ }^{*} \mathrm{P}<0.05,{ }^{* *} \mathrm{P}<0.01$ and ${ }^{* * *} \mathrm{P}<0.005$. Data were expressed as the mean \pm SD.

\section{Results}

ZSTK474 inhibits proliferation in human pancreatic adenocarcinoma cells. To evaluate the anti-tumor efficacy of ZSTK474 in human pancreatic adenocarcinoma cells, we measured cell viability of human pancreatic cancer cell lines (Colo-357, BxPC-3, MIA PaCa-2 and AsPC-1 cells) following ZSTK474 using MTT and clonogenic assays. The MTT assay showed 

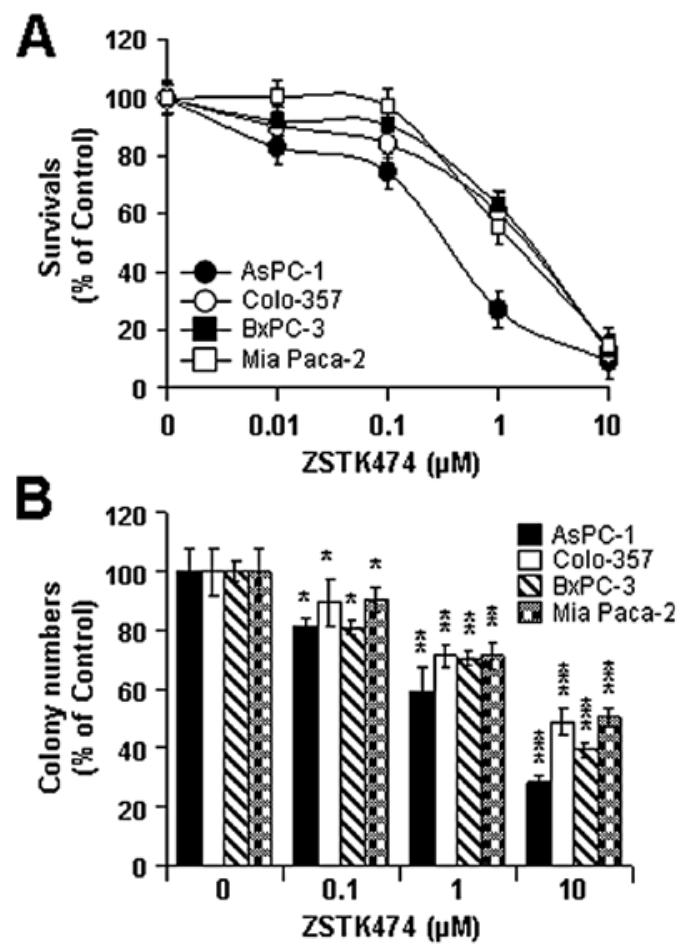

Figure 1. Effects of ZSTK474 on cell survival in various human pancreatic cancer cell lines. (A) AsPC-1, Colo-357, BxPC-3 and MIA PaCa-2 cells were treated with a various doses $(0,0.01,0.1,1$ or $10 \mu \mathrm{M})$ of ZSTK474 for $72 \mathrm{~h}$. Cell viability was measured by the MTT assay as described in Materials and methods. (B) AsPC-1, Colo-357, BxPC-3 and MIA PaCa-2 cells treated with ZSTK474 $(0,0.1,1$ or $10 \mu \mathrm{M})$ for $48 \mathrm{~h}$ were subjected to a clonogenic assay as described in Material and methods. Colony numbers were counted and calculated as a relative percentage (\%) of the untreated control cells. Experiments were repeated three times and similar results were obtained. Error bars represent the standard deviation. ${ }^{*} \mathrm{P}<0.05,{ }^{* *} \mathrm{P}<0.01$ and ${ }^{* * * *} \mathrm{P}<0.005$ significantly different from controls and $0.1,1$ and $10 \mu \mathrm{M}$ ZSTK474, respectively.

that ZSTK474 inhibits cell proliferation in a dose-dependent manner $(0,0.01,0.1,1$ or $10 \mu \mathrm{M})$ at $72 \mathrm{~h}$ (Fig. $1 \mathrm{~A})$. The $\mathrm{IC}_{50}$ of ZSTK474 was determined as $0.86,1.16,1.8$ and $0.23 \mu \mathrm{M}$ in Colo-357, BxPC-3, MIA PaCa-2 and AsPC-1 cells, respectively (Table I). In addition, ZSTK474 suppressed the colony-forming ability of human pancreatic cancer cells, indicating the potential long-term anti-tumor efficacy of ZSTK474 (Fig. 1B). In order to determine the mechanisms responsible for the sensitivity of ZSTK474, we selected three human pancreatic cancer cell lines (Colo-357, BxPC-3 and MIA PaCa-2 cells). First, we determined the phosphorylated and total protein levels of Akt, BAD and GSK3 $\beta$ after $24 \mathrm{~h}$ of treatment with ZSTK474 in various concentrations. ZSTK474 substantially reduced the level of p-Akt (S473), p-BAD (S112) and p-GSK3 $\beta$ (S9) without significantly altering their total protein levels (Fig. 2). Especially, almost complete reduction of p-Akt (S473), p-BAD (S112) and p-GSK3 $\beta$ (S9) was observed by $1 \mu \mathrm{M}$ ZSTK474 in all three human pancreatic cancer cell lines (Fig. 2). Taken together (Figs. 1 and 2), these data indicate that ZSTK474 suppresses proliferation by inhibiting the PI3K/Akt pathway and its downstream signaling.

ZSTK474 induces $G_{1}$ arrest and apoptotic cell death. Since inhibition of PI3K/Akt is known to inhibit cell proliferation and survival, we determined cell cycle alterations and cell

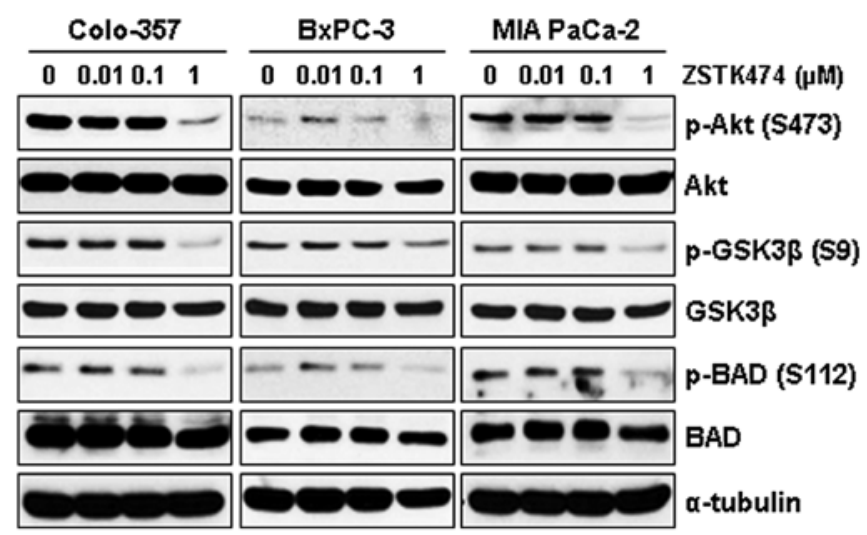

Figure 2. Effects of ZSTK474 on the phosphorylation status of Akt and its downstream substrates. Colo-357, BxPC-3 and MIA PaCa-2 cells were treated with increasing concentrations $(0,0.01,0.1$ or $1 \mu \mathrm{M})$ of ZSTK474 for $24 \mathrm{~h}$. Cells were harvested, lysed and prepared for WB analysis. Antibodies to detect the total and phosphorylated forms of Akt (S473), GSK3 $\beta$ (S9), and BAD (S112) were used. The specific phosphorylation site(s) of each kinase is indicated in parentheses. Anti- $\alpha$-tubulin antibody was used as a loading and transfer control.

Table I. In vitro anti-tumor effect(s) of ZSTK474 in human pancreatic adenocarcinoma cells.

\begin{tabular}{lc}
\hline Human pancreatic cancer cells & $\mathrm{IC}_{50}(\mu \mathrm{M})$ \\
\hline Colo-357 & 0.86 \\
BxPC-3 & 1.16 \\
MIA PaCa-2 & 1.80 \\
AsPC-1 & 0.23 \\
\hline
\end{tabular}

death after ZSTK474 treatment. Cells treated with ZSTK474 $(10 \mu \mathrm{M})$ for $48 \mathrm{~h}$ were harvested and subjected to FACS analysis. ZSTK474 increased the $\mathrm{G}_{1}$ population, compared with control cells (from 65 to $70.7 \%$ in Colo-357 and from 41.1 to $54.3 \%$ in BxPC-3; Fig. 3A), with a corresponding decrease in S-phase cells (from 25.6 to $23.2 \%$ in Colo-357 and from 51.14 to $38.48 \%$ in BxPC-3; Fig. 3A) and decreased the $\mathrm{G}_{2}$-phase cells (from 9 to $6 \%$ in Colo-357 and from 7.75 to $7.22 \%$ in BxPC-3; Fig. 3A). To further investigate whether ZSTK474 induces apoptosis, we analyzed the sub- $\mathrm{G}_{1}$ populations. Our results show that $Z$ STK474 increased the sub- $\mathrm{G}_{1}$ population in BxPC-3 cells and to a greater extent in Colo-357 cells at a high dose $(10 \mu \mathrm{M})$ (Fig. 3B). The sub- $\mathrm{G}_{1}$ population significantly increased with $10 \mu \mathrm{M}$ ZSTK474 compared with control cells. A 9-fold induction in Colo-357 cells and a 4-fold induction were observed in BxPC-3 cells, indicating that ZSTK474 induces apoptotic cell death in these cells. Moreover, Western blot analysis revealed a pattern of molecular signaling events consistent with inhibition of cell proliferation and initiation of cell death. Forty-eight hour-treatment with ZSTK474 significantly increased the cleaved forms of PARP (Fig. 3C) and activation of caspase-3 activity (Fig. 3D) in a dose-dependent manner. Taken together, the results suggest that ZSTK474 suppresses tumor growth by inducing $\mathrm{G}_{1}$-phase arrest and apoptosis in human pancreatic cancer cells. 


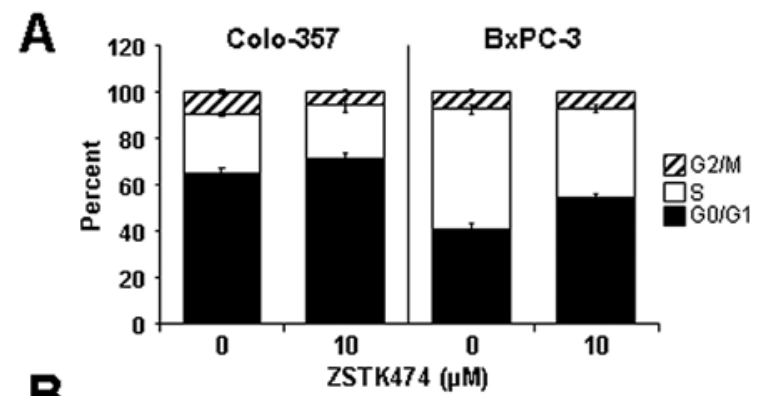

B
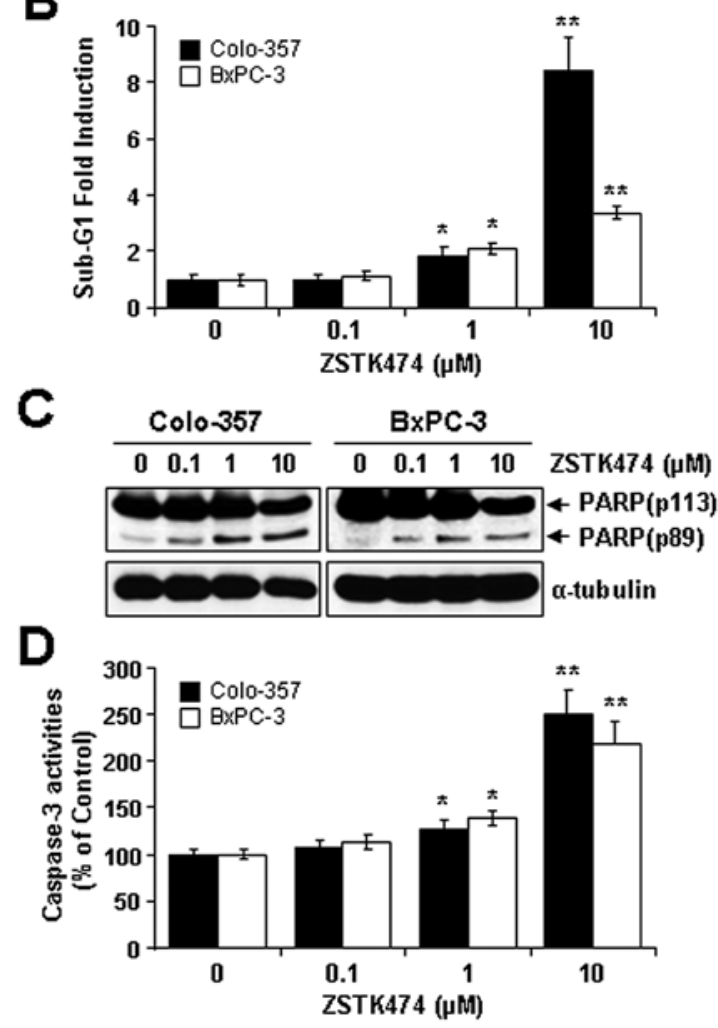

Figure 3. ZSTK474 induces $\mathrm{G}_{1}$ phase arrest and apoptotic cell death. (A) Colo357 and BxPC-3 cells were treated with $10 \mu \mathrm{M}$ ZSTK 474 for $48 \mathrm{~h}$, harvested and subjected to FACS analysis. (B-D) Colo-357 and BxPC-3 cells were treated with ZSTK474 with variable doses $(0,0.1,1$ or $10 \mu \mathrm{M})$ for $48 \mathrm{~h}$, harvested and subjected to FACS, Western blot (WB) analysis and caspase-3 activity assay. (B) The sub-G $\mathrm{G}_{1}$ population from FACS analysis was analyzed and its fold induction was plotted in a bar graph. (C) Cells treated with ZSTK474 were subjected to WB analysis. An anti-PARP antibody was used to detect its cleavage form (an apoptosis marker). (D) Cells treated with ZSTK474 were harvested and subjected to caspase-3 activity assay kit as described in Materials and methods. Caspase- 3 activities were calculated according to percentage of the untreated cells. ${ }^{*} \mathrm{P}<0.05$ and $^{* *} \mathrm{P}<0.01$, significantly different from controls.

Synergistic cytotoxic effects of GEM plus ZSTK474. Previous studies reported that GEM induces Akt activation. Accordingly, we observed that GEM treatment substantially increased phosphorylation of Akt and BAD in both Colo-357 and BxPC-3 cells (Fig. 4A). Similar results were obtained in AsPC-1 and MIA PaCa- 2 cells (data not shown). In order to study the effects of ZSTK474 on p-AKT (S473) and p-BAD (S112), cells were pre-treated with $0.5 \mu \mathrm{M}$ of GEM for $24 \mathrm{~h}$ and cultured in the presence of ZSTK474 for an additional $24 \mathrm{~h}$. As expected, ZSTK474 significantly suppressed GEM-induced phosphorylation of Akt and BAD (Fig.4B). Since GEM induces Akt activity, we treated with GEM first for $24 \mathrm{~h}$ and then with ZSTK474 for

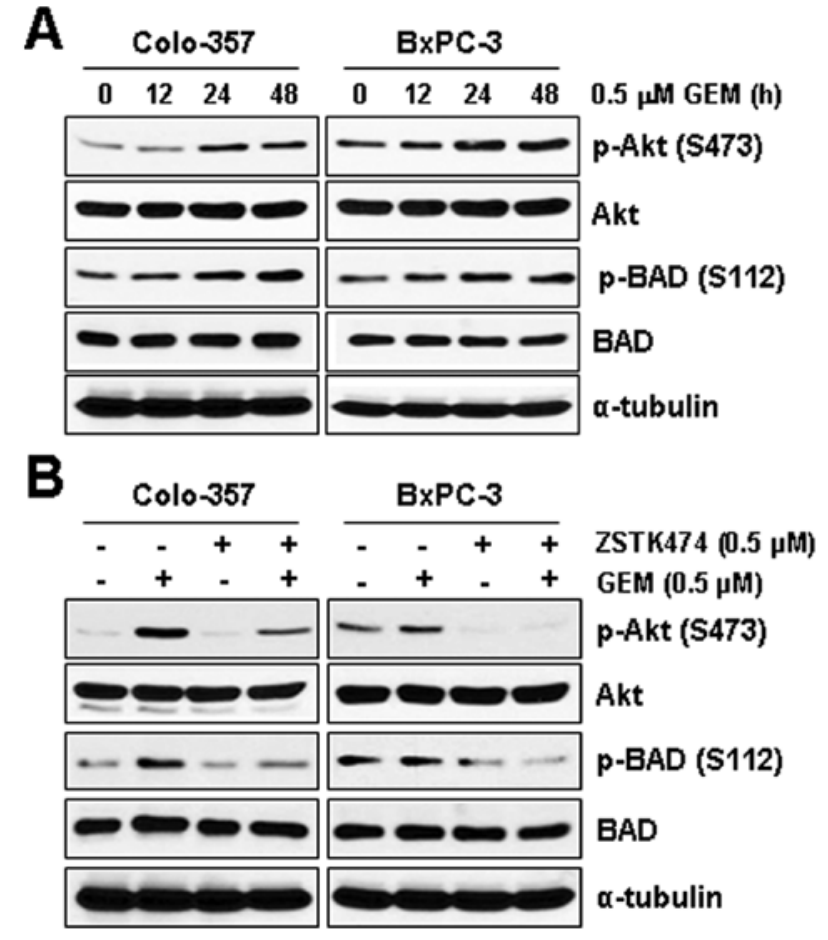

Figure 4. ZSTK474 suppresses gemcitabine (GEM)-induced Akt activity. (A) Colo-357 and BxPC-3 cells were treated with $0.5 \mu \mathrm{M}$ GEM in a time-dependent manner $(0,12,24$ or $48 \mathrm{~h})$. Cells were harvested, lysed and Western blotting (WB) was carried out for total Akt, BAD, and their phosphorylated forms: p-Akt (S473), p-BAD (S112). The phosphorylation sites are indicated in parentheses. (B) Colo-357 and BxPC-3 cells were pre-treated with $0.5 \mu \mathrm{M}$ GEM for $24 \mathrm{~h}$ and then treated with $0.5 \mu \mathrm{M}$ ZSTK474 for $24 \mathrm{~h}$. Cells were harvested, lysed and WB analysis was performed for total Akt, BAD and their phosphorylated forms: p-Akt (S473) and p-BAD (S112).

an additional $48 \mathrm{~h}$ in fixed molar concentration ratios of $0.25: 1$ and 2.5:1 in Colo-357 and BxPC-3 cells, respectively. GEM plus ZSTK474 synergistically suppressed cell survival of Colo357 and BxPC-3 cell lines (Fig. 5A). Table II shows the CI values at $\mathrm{ED}_{50}, \mathrm{ED}_{75}$, and $\mathrm{ED}_{90}$ of Colo- 357 and BxPC-3 cells. Our data show that pre-treatment with GEM results in better synergistic effects than the following sequential treatments: i) treatment with the two drugs (GEM and ZSTK474) simultaneously or ii) treatment with ZSTK474 first and then GEM (data not shown). We also obtained similar synergistic effects by the combination effect of 5-FU and ZSTK474 measured by the MTT assay (data not shown). To further address the synergism of GEM and ZSTK474, we analyzed the changes of apoptotic protein markers and caspase-3 activity. An apoptotic marker, cleaved PARP, was synergistically increased in the cells treated with GEM plus ZSTK474 (Fig. 5B). Measurement of caspase-3 activity also demonstrated that GEM plus ZSTK474 synergistically increased apoptosis in both Colo-357 and BxPC-3 cells (Fig. 5C). These results suggest that a specific blockade of PI3K/Akt by ZSTK474 induces apoptotic cell death via activation of caspase-3 and PARP cleavage in the cells pre-treated with GEM.

Synergistic inhibition of colony formation by GEM plus ZSTK474. In order to confirm the long-term effects of GEM plus ZSTK474, cells pre-treated with GEM for $24 \mathrm{~h}$ were further treated with ZSTK474. Twenty-four hours later, both drugs in 

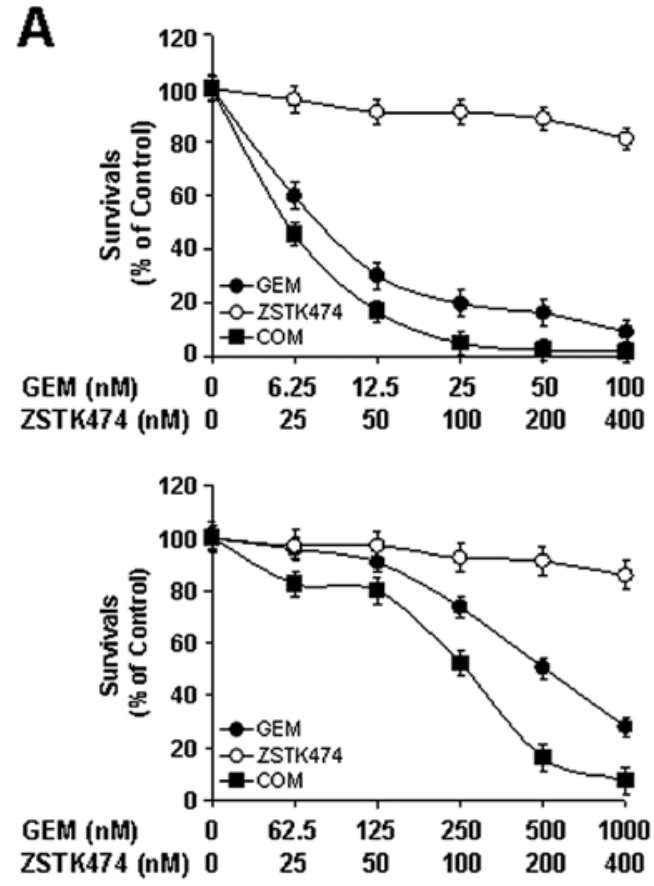

B

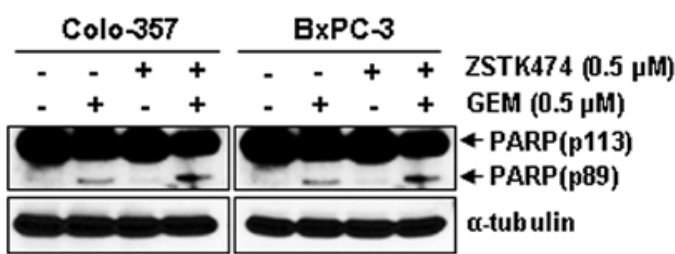

C

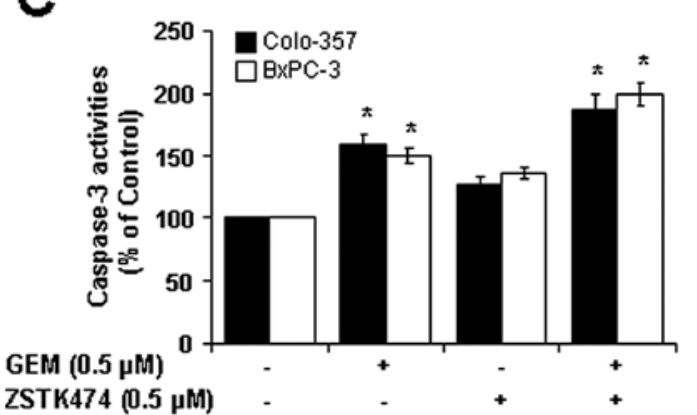

Figure 5. Short-term effects of gemcitabine (GEM) plus ZSTK474. (A) Colo-357 and BxPC-3 cells pre-treated with various doses of GEM for 24 $\mathrm{h}$ and further treated with various doses of ZSTK474 for $48 \mathrm{~h}$ with fixed molar concentration ratios of $0.25: 1$ and 2.5:1, respectively. Cell viability was determined by the MTT assay. (B) Cells were pre-treated with $0.5 \mu \mathrm{M}$ GEM for $24 \mathrm{~h}$ and treated with $0.5 \mu \mathrm{M}$ ZSTK474 for an additional $24 \mathrm{~h}$. These cells were then harvested, lysed and used for Western blot analysis. Anti-PARP antibody was used to detect apoptosis and $\alpha$-tubulin antibody was used as a loading and transfer control. (C) Cells treated with GEM plus ZSTK474 as described in (B) were lysed and caspase-3 activity was measured using the caspase- 3 colorimetric assay kit. Caspase- 3 activities were calculated as a relative percentage of the untreated control sample. Experiments were repeated three times with similar results. Error bars represent the standard deviation. $\mathrm{P}<0.05$, significantly different from controls.

culturing media were removed and cells were continuously cultured in fresh media for 14 days. Surviving colonies were stained with crystal violet, and the numbers of colonies were counted and plotted as percentages of drug treatment vs. nondrug treatment. Clonogenicity was reduced to 43.4 and $70.5 \%$ of baseline after Colo- 357 and BxPC-3 cells, respectively, were
Table II. Synergistic inhibition of cell proliferation by combination effect of gemcitabine (GEM) plus ZSTK474 in human pancreatic cancer cells. ${ }^{2}$

\begin{tabular}{lccc}
\hline & \multicolumn{3}{c}{ Combination index $(\mathrm{CI})$} \\
\cline { 2 - 4 } & $\mathrm{ED}_{50}$ & $\mathrm{ED}_{75}$ & $\mathrm{ED}_{90}$ \\
\hline Colo-357 & 0.63 & 0.40 & 0.26 \\
BxPC-3 & 0.43 & 0.41 & 0.38 \\
\hline
\end{tabular}

${ }^{a}$ CI-values were obtained from experiments using the Colo-357 and BxPC-3 cells. These CI values were calculated by the Chou and Talalay method for drug interactions using the CompuSyn software for the different fractions affected (the $\mathrm{CI}$ values at $\mathrm{ED}_{50}, \mathrm{ED}_{75}$ and $\mathrm{ED}_{90}$ ). Values of $\mathrm{CI}<1,=1$ and $>1$ indicate synergism, additive effects and antagonism, respectively.

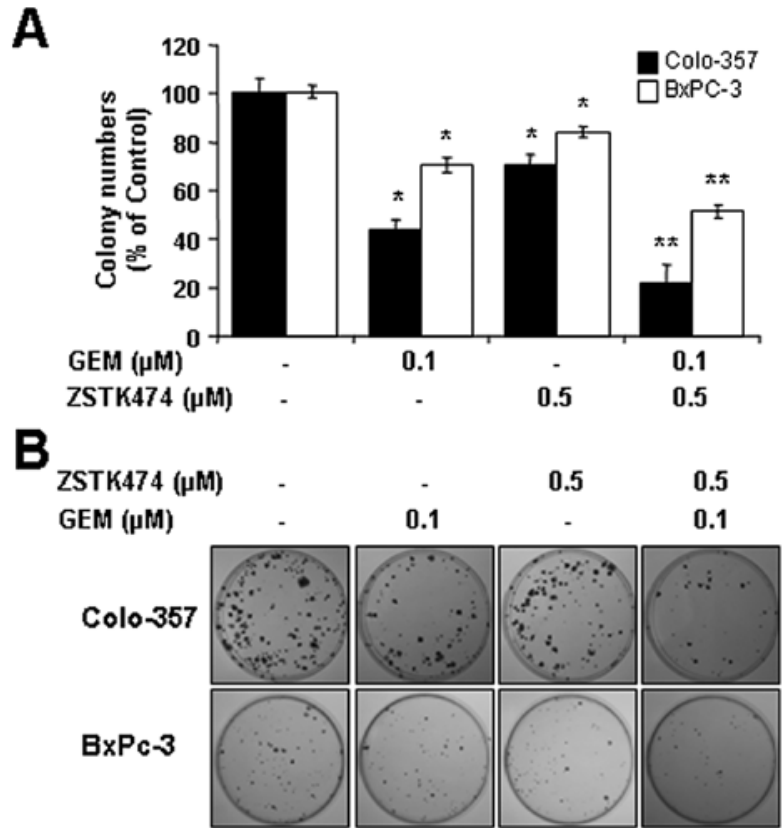

Figure 6. Long-term effects of gemcitabine (GEM) plus ZSTK474. (A) Colo357 and BxPC-3 cells pre-treated with $0.5 \mu \mathrm{M}$ GEM for $24 \mathrm{~h}$ were incubated with $0.5 \mu \mathrm{M}$ ZSTK474 for an additional $24 \mathrm{~h}$. Then, cells were trypsinized, reseeded and cultured without GEM or ZSTK474. After 14 days colony numbers were counted and calculated as a relative percentage $(\%)$ of the untreated control cells. (B) Representative photograph of the colony formation assay results are shown. Each experiment was performed in triplicate and similar results were obtained. Error bars represent the standard deviation. ${ }^{*} \mathrm{P}<0.05$ and ${ }^{* *} \mathrm{P}<0.01$, significantly different from controls.

exposed to GEM alone (Fig. 6A). Similarly, ZSTK474 alone decreased the clonogenicity to 70.3 and $83.8 \%$ of baseline in Colo-357 and BxPC-3 cells, respectively (Fig. 6A). However, clonogenicity was significantly reduced to 21.4 and $51.4 \%$ of baseline in Colo-357 and BxPC-3 cells, respectively, when these cells were treated with GEM plus ZSTK474 (Fig. 6A). A photograph of a representative clonogenic assay is shown in Fig. 6B. Taken together, the results suggest that the combination of GEM and ZSTK474 results in a synergistic decrease in the clonogenic forming potential of Colo-357 and BxPC-3 cells. 


\section{Discussion}

Our current study demonstrates that ZSTK474 treatment suppresses pancreatic cancer cell proliferation. This seems to be associated with the ability of ZSTK474 to inducing both cell cycle delay at $\mathrm{G}_{1}$ and apoptosis. A previous study shows that ZSTK474 at $10 \mu \mathrm{M}$ for $48 \mathrm{~h}$ induced only $\mathrm{G}_{1}$ arrest without inducing apoptosis in human lung, prostate and colorectal cancer cell lines (15). Raynaud et al, showed that LY294002, a PI3K/Akt inhibitor with low specificity, also affects most of its downstream protein kinases and stimulates the production of reactive oxygen species (21), which is an important apoptosis inducer. Although we do not have a clear explanation of these differential cellular responses against the two different PI3K/ Akt inhibitors, it may be due to different chemical properties of these inhibitors and/or the differential intrinsic capacity of apoptosis of the cell types used in the present vs. other studies.

Various cellular stress agents such as heat shock, UV irradiation, matrix detachment, cell cycle discordance, DNA damage and anti-tumor drugs are known to activate the PI3K/ Akt pathway (22). GEM or cisplatin induced a transient increase of the phosphorylation levels of Akt in AsPC-1 cells in a dosedependent manner $(23,24)$. Our data also demonstrate that GEM significantly increases the phosphorylation levels of Akt and its downstream signaling effectors like BAD and GSK3 $\beta$ in several human pancreatic cancer cell lines. Moreover, Wortmannin and LY294002 block the phosphorylation of Akt in PK1 and PK8 pancreatic cancer cell lines and correlates with the enhancement of GEM-induced apoptosis (8). The identification of optimal dosing regimens and sequential schedules are important for the successful clinical evaluation of cancer therapeutics, especially when therapies are combined (25). In our experiments, the sequential treatment with GEM followed by ZSTK474 caused the most synergistic cell growth inhibition. In contrast, treatment with ZSTK474 followed by GEM demonstrated a mild additive or antagonistic effect, or simultaneous treatment of ZSTK474 and GEM resulted in reduced synergistic or additive effects as determined by the MTT assay (data not shown). Although we do not exactly understand how the sequential treatment with GEM followed by ZSTK474 gives the better synergistic effects than other sequential treatment options, additional studies on this enhanced synergism may provide essential clues for choosing the best combination scheme for combination therapy of PKIs and anti-tumor agents such as GEM. Similarly, clonogenic assays from sequential treatment with GEM followed by ZSTK474 showed synergistic cell growth inhibition. Further studies are needed to confirm our MTT assay results using clonogenic assays and preclinical animal models.

Furthermore, it is known that orally administered ZSTK474 displays potent anti-tumor activity against human cancer xenografts in mice without evidence of critical toxicity, and it also reduces the phosphorylation of Akt after administration to mice (15). Thus, previous and current data support ZSTK474 as a novel anticancer drug candidate for the treatment of pancreatic cancer. In addition, ZSTK474 may be used in combination with chemotherapeutic agents to enhance treatment. In conclusion, our results show that ZSTK474 has strong anti-tumor efficacy and also enhances anti-tumor effects when combined with GEM in human pancreatic cancer cells. Our findings provide a rationale for the preclinical and clinical application of these combinations in pancreatic cancer.

\section{Acknowledgements}

I.B. has been supported by the National Institutes of Health (1R03CA152530), by Susan G. Komen for the Cure (FAS07038580) and by the Ministry of Education, Science and Technology through the National Research Foundation of Korea (R31-10069; World Class Uinversity (WCU) program).

\section{References}

1. Jemal A, Siegel R, Xu J and Ward E: Cancer statistics, 2010. CA Cancer J Clin 60: 277-300, 2010.

2. Keighley MR: Gastrointestinal cancers in Europe. Aliment Pharmacol Ther 18 (Suppl 3): 7-30, 2003.

3. Bardeesy N and Depinho RA: Pancreatic cancer biology and genetics. Nat Rev Cancer 2: 897-909, 2002.

4. Chua YJ and Zalcberg JR: Pancreatic cancer-is the wall crumbling? Ann Oncol 19: 1224-1230, 2008.

5. Pierantoni C, Pagliacci A, Scartozzi M, Berardi R, Berardi R, Bianconi $\mathrm{M}$ and Cascinu S: Pancreatic cancer: progress in cancer therapy. Crit Rev Oncol Hematol 67: 27-38, 2008.

6. Burris HA, Moore MJ, Andersen J, Green MR, Rothenberg ML, Modiano MR, Cripps MC, Portenoy RK, Storniolo AM, Tarassoff P, Nelson R, Dorr FA, Stephens CD and Von Hoff DD: Improvements in survival and clinical benefit with gemcitabine as first-line therapy for patients with advanced pancreas. J Clin Oncol 15: 2403-2413, 1997.

7. Ducreux M, Boige V and Malka D: Treatment of advanced pancreatic cancer. Semin Oncol 34: S25-S30, 2007.

8. Ng SSW, Tsao MS, Chow S and Hedley DW: Inhibition of phosphatidylinositide 3-kinase enhances gemcitabine-induced apoptosis in human pancreatic cancer cells. Cancer Res 60: 5451-5455, 2000.

9. Yokoi K and Fidler U: Hypoxia increases resistance of human pancreatic cancer cells to apoptosis induced by gemcitabine. Clin Cancer Res 10: 2299-2309, 2004.

10. Martelli AM, Faenza I, Billi AM, Manzoli L, Evangelisti C, Fala $\mathrm{F}$ and Cocco L: Intranuclear 3'-phosphoinositide metabolism and Akt signaling: new mechanisms for tumorigenesis and protection against apoptosis? Cell Signal 18: 1101-1107, 2006.

11. Izuishi $\mathrm{K}$, Kato $\mathrm{K}$, Ogura $\mathrm{T}$, Kinoshita $\mathrm{T}$ and Esumi $\mathrm{H}$ : Remarkable tolerance of tumor cells to nutrient depravation: possible new biochemical target for cancer therapy. Cancer Res 60: 6201-6207, 2000.

12. Bondar VM, Sweeney-Gotsch B, Andreeff M, Mills GB and McConkey DJ: Inhibition of the phosphatidylinositol 3'-kinaseAkt pathway induces apoptosis in pancreatic carcinoma cells in vitro and in vivo. Mol Cancer Ther 1: 989-997, 2002.

13. Workan P, Clarke PA, Raynaud FI and van Montfort RL: Drugging the PI3 kinome: from chemical tools to drugs in the clinic. Cancer Res 70: 2146-2157, 2010.

14. Yaguchi S, Izumisawa Y, Sato M, Nakagane T, Koshimizu I, Sakita K, Kato M, Yoshioka K, Sakato M and Kawashima S: In vitro cytotoxicity of imidazolyl-1,3,5-triazine derivatives. Biol Pharm Bull 20: 698-700, 1997.

15. Yaguchi S, Fukui Y, Koshimizu I, Yoshimi H, Matsuno T, Gouda H, Hirono S, Yamazaki K and Yamori T: Anti-tumor activity of ZSTK474, a new phosphatidylinositol 3-kinase inhibitor. J Natl Cancer Inst 98: 546-556, 2006.

16. Kong D, Dan S, Yamazaki K and Yamori T: Inhibition profiles of phosphatidylinositol 3-kinase inhibitors against PI3K superfamily and human cancer cell line panel JFCR39. Eur J Cancer 46: 1111-1121, 2010.

17. Dong DX and Yamori T: ZSTK474, a novel phosphatidylinositol 3-kinase inhibitor identified using the JFCR39 drug discovery system. Acta Pharmacol Sin 31: 1189-1197, 2010.

18. Kong D and Yamori T: ZSTK474 is an ATP-competitive inhibitor of class I phosphatidylinositol 3-kinase isoforms. Cancer Sci 98: 1638-1642, 2007.

19. Dan S, Yoshimi H, Okamura M, Mukai Y and Yamori T: Inhibition of PI3K by ZSTK474 suppressed tumor growth not via apoptosis but G0/G1 arrest. Biochem Biophys Res Commun 379: 104-109, 2009. 
20. Chou TC and Talalay P: Quantitative analysis of dose-effect relationships: the combined effects of multiple drugs and enzyme inhibitors. Adv Enzyme Regul 22: 27-55, 1984.

21. Raynaud FI, Eccles S, Clarke PA, Hayes A, Nutley B, Alix S, Henley A, Di-Stefano F, Ahmad Z, Guillard S, Bierke LM, Kelland L, Valenti M, Patterson L, Gowan D, de Haven Brandon A, Hayakawa M, Kaizawa H, Koizumi T, Ohishi T, Patel S, Saqhir N, Parker P, Waterfield M and Workman P: Pharmacologic characterization of a potent inhibitor of class I phosphatidylinositide 3 kinases. Cancer Res 67: 5840-5850, 2007.

22. Clark AS, West K, Streicher S and Dennis PA: Constitutive and inducible Akt activity promotes resistance to chemotherapy, trastuzumad or tamoxifen in breast cancer cells. Mol Cancer Ther 1: 707-717, 2002.

23. Yotsumoto F, Fukami T, agi H, Funakoshi A, Yoshizato T, Kunoki $\mathrm{M}$ and Miyamoto S: Amphiregulin regulates the activation of ERK and Akt through epidermal growth factor receptor and HER3 signals involved in the progression of pancreatic cancer. Cancer Sci 101: 2351-2360, 2010.
24. Fujiwara M, Izuishi K, Sano T, Hossain MA, Kimura S, Masaki T and Suzuki Y: Modulating effect of the PI3-kinase inhibitor LY294002 on cisplatin in human pancreatic cancer cells. J Exp Clin Cancer Res 27: 76, 2008.

25. Hirai H, Sootome H, Nakatsuru Y, Miyama K, Taquchi S, Tsujioka K, Ueno Y. Hatch H, Majumder PK, Pan BS and Kotani H: MK-2206, an allosteric Akt inhibitor, enhances anti-tumor efficacy by standard chemotherapeutic agents or molecular targeted drugs in vitro and in vivo. Mol Cancer Ther 9: 1956-1967, 2010. 